\title{
QUEEN'S
UNIVERSITY
BELFAST
}

\section{Effect of controlled periodic-based illumination on the photonic efficiency of photocatalytic degradation of methyl orange}

Tokode, O. I., Prabhu, R., Lawton, L. A., \& Robertson, P. K. J. (2012). Effect of controlled periodic-based illumination on the photonic efficiency of photocatalytic degradation of methyl orange. Journal of Catalysis, 290, 138-142. https://doi.org/10.1016/j.jcat.2012.03.011

Published in:

Journal of Catalysis

Document Version:

Peer reviewed version

Queen's University Belfast - Research Portal:

Link to publication record in Queen's University Belfast Research Portal

Publisher rights

Copyright 2012 Elsevier Inc. All rights reserved.

\section{General rights}

Copyright for the publications made accessible via the Queen's University Belfast Research Portal is retained by the author(s) and / or other copyright owners and it is a condition of accessing these publications that users recognise and abide by the legal requirements associated with these rights.

Take down policy

The Research Portal is Queen's institutional repository that provides access to Queen's research output. Every effort has been made to ensure that content in the Research Portal does not infringe any person's rights, or applicable UK laws. If you discover content in the Research Portal that you believe breaches copyright or violates any law, please contact openaccess@qub.ac.uk. 
Effect of controlled periodic based illumination on the photonic efficiency of photocatalytic degradation of methyl orange

Oluwatosin I. Tokode, Radhakrishna Prabhu, Linda A Lawton and Peter K. J. Robertson.

IDeaS, Innovation, Design and Sustainability Research Institute, Robert Gordon University, Schoolhill, Aberdeen, AB10 1FR, UK.

\section{Abstract}

The use of controlled periodic illumination with UV LEDs for enhancing photonic efficiency of photocatalytic decomposition processes in water has been investigated using methyl orange as a model compound. The impact of the length of light and dark time periods ( $\mathrm{T}_{\mathrm{ON}} / \mathrm{T}_{\mathrm{OFF}}$ times) on photodegradation and photonic efficiency using a UV LED illuminated photoreactor has been studied. The results have shown an inverse dependency of the photonic efficiency on duty cycle and a very little effect on TON $_{\text {on }}$ TofF time periods, indicating no effect of rate limiting steps through mass diffusion or adsorption/desorption in the reaction. For this reactor, the photonic efficiency under controlled periodic illumination (CPI) matches to that of continuous illumination, for the same average UV light intensities. Furthermore, under CPI conditions, the photonic efficiency is inversely related to the average UV light intensity in the reactor, in the millisecond time regime. This is the first study that has investigated the effect of controlled periodic illumination using UV LED sources. The results not only enhances the understanding of the effect of periodic illumination on photocatalytic processes but also provides a greater insight to the potential of these light sources in photocatalytic reactions.

\section{Keywords}

Photocatalysis, Photonic efficiency, Titanium dioxide, UV-LED, Photoreactor, Controlled periodic illumination. 


\section{I ntroduction}

The process of photocatalytic oxidation has been reported to be an effective method for the remediation of a broad range of organic compounds that pollute the environment [1-6]. Photocatalytic oxidation takes place when light (photons) having energy (hv) equal to or greater than the bandgap $\left(E_{b g}\right.$ ) of the semiconductor photocatalyst is absorbed by material. This results in charge separation due to the promotion of an electron $\left(e_{c b}{ }^{-}\right)$from the valence to the conduction band, generating a hole $\left(\mathrm{h}_{\mathrm{vb}}{ }^{+}\right)$at the valence band. The resulting electron/hole pair can subsequently be involved in redox reactions at the semiconductor surface. Incident photons that initiate this process are, however, not efficiently used and this results in low quantum yields or photonic efficiencies that have been reported in the photocatalytic oxidation of aqueous pollutants $[7,8]$.

Controlled periodic illumination (CPI) which is based on a series of alternate light and dark periods ( $\mathrm{T}_{\mathrm{ON}} / \mathrm{T}_{\mathrm{OFF}}$ ) has been previously reported as a means of increasing the photonic efficiency and improving the conversion rate of reactants or formation of products in $\mathrm{TiO}_{2}$ photocatalysis [9-12]. It is based on a hypothesis that continuous introduction of photons may result in the build-up of charges and photogenerated intermediates such as superoxide ion and hydroxyl radicals. These intermediate species are involved in the photocatalytic oxidation of the organic substrate but can also participate in reactions that favour electron-hole recombination resulting in a low efficiency of the oxidation process [12]. It was previously suggested that periodically illuminating the $\mathrm{TiO}_{2}$ particle at short intervals would inhibit the build-up of intermediates and reduce the rate of recombination reactions. A transient kinetic model by Upadhya and Ollis suggested rapid oxidation of the organic substrate during light on periods ( $T_{\mathrm{ON}}$ ) was responsible for the high photonic efficiencies under CPI [11]. In more recent studies, the CPI effect was attributed to mass transport limitations of oxygen or the substrate to the catalyst surface by Buechler et al. [13], while Cornu et al. 
[8] found no improved quantum yield of formate oxidation under CPI at low photon absorption rates.

Periodic illumination studies have previously involved light and dark periods of short duration, sometimes in the milliseconds time-scale. For example Sczechowski et al. [12] reported irradiated periods as low as 72 ms in their CPI study of the photocatalytic decomposition of the formate ion. An open channel reactor with a light bulb equipped with a parabolic aluminium reflector was used. Light and dark times were created by wrapping sections of the light bulb with aluminium foil; the illumination time corresponded with the length of exposed sections as the slurry flowed underneath. Cornu et al. employed a UV-A lamp along with an optical chopper to generate pulses as low as $22 \mathrm{~ms}$ while studying the mechanism of photocatalysis under CPI of methyl orange which degrades about 100 times slower than formate under similar conditions [14].

In recent years, there has been tremendous progress in LED lifetime, illumination efficiency and total lumen output [15]. This new generation high-bright UV-LEDs can be electronically controlled, allowing variable on and off times on a millisecond time-scale. Consequently these sources may be more effective for CPI than incandescent lamps which cannot be turned on and off alternately at a similar time-scale therefore requiring the use of complex mechanical shutters [16]. Furthermore, using an electronic controller, it may be possible to independently control the ToN and $T_{\text {OFF, }}$ hence varying the photon absorption time and the time for rate limiting steps in the photocatalytic process. These LEDs could potentially be utilised in large scale reactors allowing periodic illumination to be used in such processes. Such application of periodic illumination would be more challenging using traditional UV irradiations sources as incorporation of mechanical shutters in such reactors would require more complex engineering and hence cost.

This study investigates the effect of light and dark time periods on photonic efficiency of methyl orange degradation by employing $a$ controlled experiment approach using a novel UV-LED illuminated photoreactor. The photonic efficiency remained as the dependent variable 
throughout the different sets of experiments, while the period, $\mathrm{T}_{\mathrm{ON}}$ and Toff each served as controlled variables in one set, and independent variable in other sets of experiments, hence providing a critical evaluation of their effects on photonic efficiency. The LEDs used in this study have a narrow emission spectrum with a peak at $360 \mathrm{~nm}$, unlike conventional UV lamps which have broad emission spectra over a range of wavelengths. Methyl orange was selected for these studies as it displayed virtually no absorption of the UV light emitted from the LEDs. This ensured that a photocatalytic process was solely responsible for the dye degradation and not photolysis as exhibited by dyes such as acid red 51 which easily degrade by photolysis under broad UV illumination [17]. The study concludes with a study of photonic efficiency under CPI at different maximum intensity, I $\max$ and makes photonic efficiency comparison between periodic and continuous illumination at the same average power.

\section{Materials and Methods}

\subsection{Materials}

A $100 \mathrm{~mL}$ aqueous solution of $2.5 \times 10^{-5} \mathrm{M}$ of Methyl Orange (MO) (SigmaAldrich) was prepared in distilled water. $\mathrm{TiO}_{2}$ (Degussa P25) was used as received and a $5 \mathrm{~g} \mathrm{~L}^{-1}$ photocatalyst suspension was used in all the photocatalytic decomposition reactions.

\subsection{Photoreactor Unit}

The photoreactor unit was an annular type slurry reactor having outer and inner cylindrical chambers; the outer chamber was $59 \mathrm{~mm}$ high with an external and internal diameter of $110 \mathrm{~mm}$ and $105 \mathrm{~mm}$ respectively. A $100 \mathrm{~mL}$ aqueous solution of the pollutant was held in the inner chamber and stirred with a magnetic stirrer (I kamag RCT) (figure 1). An array of LEDs in strips was attached to the outer chamber to provide irradiation from all sides, this chamber was coated with reflective aluminium film to minimise photonic loss from the reactor. 
Figure 1.

\subsection{UV-LED Light source}

LED sources (FoxUV ${ }^{T M}$ ) used in the study were $5 \mathrm{~mm}$ round with wavelength peak at $360 \mathrm{~nm}$, viewing angle of $15^{\circ}$ and typical radiant power maintenance of $>90 \%$ past 1200 hours [17]. The LEDs were characterized in our lab to have an average radiant power of $435 \mu \mathrm{W}$. The LEDs were mounted on strips of printed circuit board (PCB) with a spacing of $8 \mathrm{~mm}$, six per strip and six strips were affixed to the outer cylindrical chamber, $450 \mathrm{~mm}$ apart to give a multi-directional array and powered by a power supply (Farnell TOP S/2).

\subsection{Method}

The experiments were conducted in a dark room typically for 170 minutes including 30 minutes to allow for dark adsorption equilibration at ambient temperature. Sample aliquots of $1 \mathrm{~mL}$ was taken in triplicate at intervals with a syringe (B-D plastiplak) and filtered with a Whatman $0.45 \mu \mathrm{m}$ filter. Methyl orange absorbance was measured at its highest peak of $462 \mathrm{~nm}$ [18] with a Perkin Elmer Lambda950 UV-VIS spectrometer and methyl orange concentration was determined from the calibration curve.

Light pulses were generated with an electronic astable multivibrator circuit with the light time ( $\mathrm{T}_{\mathrm{ON}}$ ) and dark time ( $\mathrm{T}_{\mathrm{OFF}}$ ) cycles different for each experiment. The incident photon rate from the UV LEDs determined by the ratio of the total energy of the LEDs to the energy of a single photon, was calculated to be $4.85 \times 10^{-8}$ einsteins $\mathrm{L}^{-1} \mathrm{~s}^{-1}$ and the reaction rate was calculated as change in concentration with time, $\left[\left(C_{1}-C_{0}\right) /\right.$ time $]$ where $C_{0}$ is the concentration at the start of illumination and $C_{1}$ is the final concentration. Photonic efficiency for the photocatalytic degradation of methyl orange, $\Phi$ was calculated in all cases as the reaction rate of methyl orange degradation divided by the incident photon rate [19]: 


$$
\Phi=\frac{\text { Reaction rate }\left(\mathrm{M} \mathrm{s}^{-1}\right)}{\text { Incident photon rate }\left(\mathrm{M} \mathrm{s} s^{-1}\right)}
$$

\section{Results and discussion}

Three sets of experiments were carried out to investigate the effect of light and dark time ( $T_{\mathrm{ON}}$ and $\mathrm{T}_{\mathrm{OFF}}$ ) periods on the photonic efficiency of the photocatalytic degradation of methyl orange under low intensity UV light. Maximum UV light intensity, I $\max$ entering the reactor was $178 \mu \mathrm{Wcm}^{-2}$. In the first set of experiments, $T_{\text {ON }}$ and TofF $_{\text {ofimes }}$ were varied while the period remained constant, i.e. given the primary steps of charge-carrier generation and recombination which occur during the light time;

$$
\begin{gathered}
\mathrm{TiO}_{2}+\mathrm{hv} \rightarrow \mathrm{e}_{\mathrm{cb}}^{-}+\mathrm{h}_{\mathrm{wb}}^{+} \\
\mathrm{e}_{\mathrm{cb}}^{-}+\mathrm{h}_{\mathrm{vb}}^{+} \rightarrow \text { heat }
\end{gathered}
$$

and the slower steps of radical formation and interfacial charge transfer, which occur during the dark time (or light time) depending on the pulse duration. The various steps for this experiment were constrained within a period of $\sim 1 \mathrm{~s}$, while the duty cycle, $\gamma$ varied accordingly with TON and TofF variations. Ton ranged from $72 \mathrm{~ms}$ to continuous illumination. The percentage degradation of methyl orange increased as the average intensity, $I_{\text {avg }}$ increased as shown in figure 2 , where $\left(I_{\text {avg }}=\gamma I_{\max }\right)$ and $\gamma$ is the duty cycle $\left[\gamma=\mathrm{T}_{\mathrm{ON}} /\left(\mathrm{T}_{\mathrm{ON}}+\mathrm{T}_{\mathrm{OFF}}\right)\right]$.

\section{Figure 2.}

The dependence of photonic efficiency on $\mathrm{I}_{\text {avg }}$ and $\gamma$ are shown in figure $3(a)$. The highest photonic efficiency was recorded the lowest value of $I_{\text {avg }}$ and $\gamma$ and vice versa indicating an inversely proportional relationship between photonic efficiency and both $\mathrm{I}_{\text {avg }}$ and $\gamma$. The variation of photonic efficiency with $T_{O N}$ and $T_{\text {OFF }}$ are shown in figure $3(b)$ and the trends predict a direct link between $T_{O N}$ and $T_{\text {OFF }}$ times and photonic efficiency. Photonic 
efficiency increases with $T_{O N}$ reduction because of a corresponding increase in Toff. This implies a brief period of charge-carrier generation, eq (2) and less time for charge-carrier recombination, eq (3) influenced by rising levels of $e_{c b}{ }^{-}$; which is the primary reason for low efficiency [20]. The corresponding increase in Toff also gives rise to the titration of holes by the high electron concentration, eq (3) effectively stopping hole oxidation reactions while giving ample time for the interfacial charge transfer of electrons to adsorbed oxygen or adsorption of oxygen/substrate to the $\mathrm{TiO}_{2}$ surface; two steps previously identified as rate-limiting in the photocatalytic process[13, 21].

$$
\begin{gathered}
\mathrm{O}_{2}+\mathrm{e}^{-} \rightarrow \mathrm{O}_{2}^{-} \\
\mathrm{O}_{2 \text { hneld }} \rightarrow \mathrm{O}_{2} / \mathrm{TiO}_{2} \\
\mathrm{MO}_{\text {burls }} \rightleftharpoons \mathrm{MO} / \mathrm{TiO}_{2}
\end{gathered}
$$

\section{Figure 3.}

For the second set of experiments, the individual impact of the dark time ( TofF $_{\text {) }}$ on photonic efficiency was investigated. The illumination time, ToN $_{\text {N }}$ was kept constant at $1.0 \mathrm{~s}$, corresponding to an incident photon rate of $4.85 \times 10^{-8}$ einsteins $\mathrm{L}^{-1} \mathrm{~S}^{-1}$ for all values of $\gamma$, hence charge-carrier generation and recombination rates, eq (2) and (3) and any other reactions occurring during TON were controlled and identical for varying values of $\gamma$. The dark time, Toff was varied incrementally, hence the main events of $\mathrm{T}_{\mathrm{OFF}}$ (adsorption/desorption) were monitored at $\mathrm{T}_{\mathrm{OFF}, \min }=0.1 \mathrm{~s}$ to $\mathrm{T}_{\mathrm{OFF}, \max }=1.1 \mathrm{~s}$ and the corresponding photonic efficiency variation is shown in Figure 4. The dark time influenced photonic efficiency as reported by Stewart and Fox who achieved a 1.8 fold improvement when the dark time was increased from $0.1 \mathrm{~s}$ to $1 \mathrm{~s}$ [10]. A similar improvement in photonic efficiency was observed in this study with an increase in the dark time. It is believed that this is a result of depleted oxygen being readsorbed onto the surface during the dark time, with some re-adsorption of methyl orange onto the $\mathrm{TiO}_{2}$ surface as well.

$$
\mathrm{O}_{2 \text { hnd }} \rightarrow \mathrm{O}_{2} / \mathrm{TiO}_{2} \quad \begin{gathered}
\text { Adsorption } \\
\text { on TiO } \\
\text { surface }
\end{gathered}
$$




$$
\mathrm{MO}_{\text {buth }} \rightleftharpoons \mathrm{MO} / \mathrm{TiO}_{2}
$$

The oxygen subsequently reacts with the excess electrons hence inhibiting recombination with holes. This improvement is, however, sensitive to the oxygen re-adsorption/reduction rate which is a slow process and has previously been suggested to be the rate-limiting step in photocatalytic reactions [21].

When the time regimes were inverted for the third set of experiments, so that Toff was maintained at $1.1 \mathrm{~s}$ thereby constraining dark time events within that time frame and Ton varied from $0.1 \mathrm{~s}$ to $1.1 \mathrm{~s}$, thus, incident photon rates had a minimum value of $4.85 \times 10^{-9}$ Einstein $\mathrm{L}^{-1} \mathrm{~s}^{-1}$ and maximum value of $5.34 \times 10^{-8}$ Einstein $\mathrm{L}^{-1} \mathrm{~s}^{-1}$, there was also an improvement in photonic efficiency. This improved photonic efficiency reached a minimum value of 6.5 , at the maximum incident photon rate because of the prolonged occurrence of reactions as per eq (2) and (3) without a corresponding increase in time for reactions as per eq (4) to (6). This demonstrates the importance of both the light and dark times when $\mathrm{TiO}_{2}$ is periodically illuminated, but while increasing $\mathrm{T}_{\mathrm{OFF}}$ from $0.1 \mathrm{~s}$ to 1.1 $s$ resulted in a $38 \%$ increase in photonic efficiency, decreasing $T_{O N}$ from $1.1 \mathrm{~s}$ to $0.1 \mathrm{~s}$ increased the photonic efficiency by $89 \%$ (figure 4 ). This observation is in agreement with the conclusion by Ollis and Upadhya that the dark time is primarily devoted to the repopulation of the surface with sufficient oxygen as a reducible species and for removal of electrons that will be produced in the next light period [11].

\section{Figure 4.}

When the results from all three experiments are plotted together on a graph, it demonstrates a general increase in photonic efficiency as the duty cycle or average intensity decreases irrespective of a decrease in ToN or increase in TofF (fig. 5). The trend shows that the photonic efficiency depends on duty cycle rather than the individual variation of Ton and ToFf times. These results agree with the findings of Cornu et al. [8] that the reaction is not limited by mass diffusion or by adsorption/desorption from $\mathrm{TiO}_{2}$ powder surface. 


\section{Figure 5.}

The dependency of photonic efficiency of the reactor on UV light power $\left(I_{\max }\right)$ under CPI was studied at two different light power densities $\left(I_{\max }=\right.$ $178 \mu \mathrm{Wcm}^{-2}$ and $I_{\max }=119 \mu \mathrm{Wcm}^{-2}$ ). By varying the power densities, the photons per light pulse each set of the experiments were different while keeping the $\mathrm{T}_{\mathrm{ON}}$ (this would provide same time at different absorption rates for reactions to occur based on eq (2) and (3) \& Toff same (same time for reactions as per eq (4) to (6). Previous studies have reported that there was generally an improvement in photonic efficiency when reactors were irradiated at relatively low light intensities [22]. This efficiency gradually increased until the reaction became photon-limited [23]. Since photonic efficiency was highest at the shortest Ton (lowest $\mathrm{I}_{\text {avg }}$ ) the intensity was lowered to $I_{\max }=119 \mu \mathrm{Wcm}^{-2}$ to investigate the actual effect of CPI on the photonic efficiency. Figure 6 shows the photodegradation and corresponding photonic efficiency variation with duty cycle. The lower power density showed better photonic efficiency.

\section{Figure 6}

Further studies were carried out to understand the photonic efficiency under low power densities for CPI and continuous illumination. We have observed an increase in photonic efficiency with reduction in power densities under continuous illumination $(\gamma=1)$. The photonic efficiency at periodic illumination was found to be equivalent to that under continuous illumination when the average power was similar at low light intensities (fig. 7). Buechler et al. [24] reported higher photonic efficiency for CPI compared to continuous illumination which gradually approached that of continuous illumination as the light intensity was reduced. Thus both illumination approaches achieved high photonic efficiencies by reducing the average light intensity entering the reactor while producing enough photons to give a reasonably high conversion rate at the same time. This suggests that the electron-hole pair generation and further carrier recombination in $\mathrm{TiO}_{2}$ were not limiting the reaction at these low light power levels. 


\section{Figure 7.}

Furthermore, we have observed lower photonic efficiencies in our experiment compared to Buechler et al. [24] and this might be due to the nature of the compounds [25] and/or the LED sources used in this study, UV LEDs emit in a shorter spectral band (typically from $355 \mathrm{~nm}-370 \mathrm{~nm}$ ) compared to UV-A lamps which have broad emission spectrum (typically $315 \mathrm{~nm}-400 \mathrm{~nm}$ ). This was responsible for higher absorption by $\mathrm{TiO}_{2}$ particles due to the better match of their absorption spectra. The use of next generation high bright, low wavelength UV LEDs would help improve the photonic efficiencies of the photocatalytic process.

\section{Conclusion}

The photonic efficiency of photocatalytic processes achieved with controlled periodic UV illumination using UV LEDs have been studied using methyl orange as a model pollutant. The results have shown an increase in photonic efficiency with reducing duty cycle and it depends on duty cycle rather than the light or dark time periods, in the millisecond region. This indicates that the reaction is not limited by mass diffusion or by adsorption/desorption from $\mathrm{TiO}_{2}$ powder surface. Furthermore, under lower UV-power densities, the photonic efficiency for CPI increased with decreasing power levels. For the photoreactor used in this study (with lower power densities), the photonic efficiency from CPI followed the same trend as in continuous illumination and thus indicating a non-limited carrier recombination process. This study does not contradict any of the previous reports on higher photonic efficiency due to periodic illumination under high photonic absorption rates but provides better insight into the UV LED illumination based photocatalytic reaction process. Further research to understand the effect of higher photonic absorption rate on photonic efficiency using UV LEDs is currently ongoing.

\section{Acknowledgements.}


The authors would like to thank the Scottish Funding Council who funded R. Prabhu's lectureship through the Northern Research Partnership's research pooling initiative in engineering. 


\section{References}

[1] R.M. Hoffmann, T.S. Martin , W. Choi , W.D. Bahnemann, Chem. Rev. 95 (1995) 69-96.

[2] L.A. Linsebigler, G. Lu, T.J. Yates, Chem. Rev. 95 (1995) 735-758.

[3] A. Mills, S. Le Hunte, J. Photochem. Photobiol. A. 108 (1997) 1.

[4] D. Bahnemann, D. Bockelmann, R. Goslich, Solar Energy Materials 24 (1991) 564.

[5] D. Friedmann, C. Mendive, D. Bahnemann, Applied Catalysis B: Environmental 99 (2010) 398.

[6] P.K.J. Robertson, D.W. Bahnemann, J.M.C. Robertson, F. Wood, in: P. Boule, D.W. Bahnemann, P. K. J. Robertson (Eds.), Environmental Photochemistry Part II, Springer-Verlag Berlin Heidelberg. (2005, pp.) 367-424.

[7] T. Van Gerven, G. Mul, J. Moulijn, A. Stankiewicz, Chemical Engineering and Processing: Process Intensification 46 (2007) 781.

[8] J.G.C. Cornu , A.J. Colussi , R.M. Hoffmann, J. Phys. Chem. B 105 (2001) 1351-1354.

[9] J.K. Buechler, D.R. Noble, A.C. Koval , A.W. Jacoby, Ind. Eng. Chem. Res. 38 (1999) 892-896.

[10] G. Stewart , A.M. Fox , Res. Chem. Interm. 21 (1995) 933-938(6).

[11] S. Upadhya , F.D. Ollis, J. Phys. Chem. B 101 (1997) 2625-2631.

[12] J.G. Sczechowski, C.A. Koval, R.D. Noble, J. Photochem. Photobiol. A. 74 (1993) 273.

[13] K.J. Buechler, T.M. Zawistowski, R.D. Noble, C.A. Koval, Ind Eng Chem Res 40 (2001) 1097. 
[14] C.J.G. Cornu, A.J . Colussi, M.R. Hoffmann, The Journal of Physical Chemistry B 107 (2003) 3156.

[15] D.S. Mehta, K. Saxena, S.K. Dubey, C. Shakher, J Lumin 130 (2010) 96.

[16] H. Chen, Y. Ku, A. Irawan, Chemosphere 69 (2007) 184.

[17] Fox Group Optoelectronics, FoxUV LEDs, 360nm 5mm round, Available online. Last accessed 12.08.2011. URL:

http://www.thefoxgroupinc.com/index.php?\%20\%20option=com_content\&view=article\&id= $\underline{74 \& \text { Itemid }=68}$, .

[18] P. He, L. Wang, J. Xue, Z. Cao, Environmental Technology 31 (2010) 417-422.

[19] S. Sakthivel, M.V. Shankar, M. Palanichamy, B. Arabindoo, D.W. Bahnemann, V. Murugesan, Water Res. 38 (2004) 3001.

[20] J.M. Herrmann, Topics in Catalysis 34 (2005) 49.

[21] H. Gerischer, A. Heller, J. Electrochem. Soc. 139 (1992) 113-118.

[22] J.G. Sczechowski, C.A. Koval, R.D. Noble, Chemical Engineering Science 50 (1995) 3163.

[23] Y. Ohko, K. Hashimoto, A. Fujishima, J. Phys. Chem. A 101 (1997) 8057-8062.

[24] J.K. Buechler, H.C. Nam, M.T. Zawistowski, D.R. Noble, A.C. Koval, Industrial \& Engineering Chemistry Research 38 (1999) 1258-1263.

[25] C. Wang, J. Rabani, D.W. Bahnemann, J.K. Dohrmann, J. Photochem. Photobiol. A. 148 (2002) 169. 


\section{Captions for Figures}

Figure 1. (a) Schematic diagram of UV-LED photoreactor: 1. Inner chamber; 2. stir bar; 3. UV LEDs attached to outer chamber; 4. magnetic stirrer; 5. power supply.(b) Diagrammatic representation of light pulse showing $T_{O N}$ and $T_{\text {OFF }}$ times.

Figure 2. Effect of $\mathrm{I}_{\text {avg }}$ on the degradation of methyl orange under CPI

Figure 3. (a) Effect of $I_{\text {avg }}\left(-\diamond_{-}\right)$and $Y(-\square-)$ on photonic efficiency under CPI (b) effect of TON (- $\square-)$ and TofF $(-\diamond-)$ on photonic efficiency under CPI.

Figure 4. Effect of varying $T_{\text {ON }}$ at constant $T_{\text {OFF }}(-\square-)$ and varying $T_{\text {OFF }}$ at constant $\mathrm{T}_{\mathrm{ON}}\left(-\diamond_{-}\right)$on photonic efficiency.

Figure 5. General photonic efficiency trend of methyl orange degradation at various $T_{\text {ON }}$ and $T_{\text {OFF }}$ cycles; varying $T_{\text {ON }}$ and constant $T_{\text {OFF }}$ (- $\square$-), varying $T_{\text {ON }}$ and $T_{\text {OFF }}(-\diamond-)$, varying $T_{\text {OFF, }}$, constant $T_{\text {ON }}(-\Delta-)$

Figure 6. (a) Photonic efficiency of methyl orange degradation at different light intensities, (b) Percentage degradation of methyl orange after 170 minutes: I $I_{\max }=178 \mu \mathrm{Wcm}^{-2}\left(-\diamond_{-}\right), I_{\max }=119 \mu \mathrm{Wcm}^{-2}(-\square-)$.

Figure 7. Comparison of photonic efficiency under CPI $\left(-\diamond_{-}\right)$and continuous illumination (- $\square$-) at various average powers 
(a)

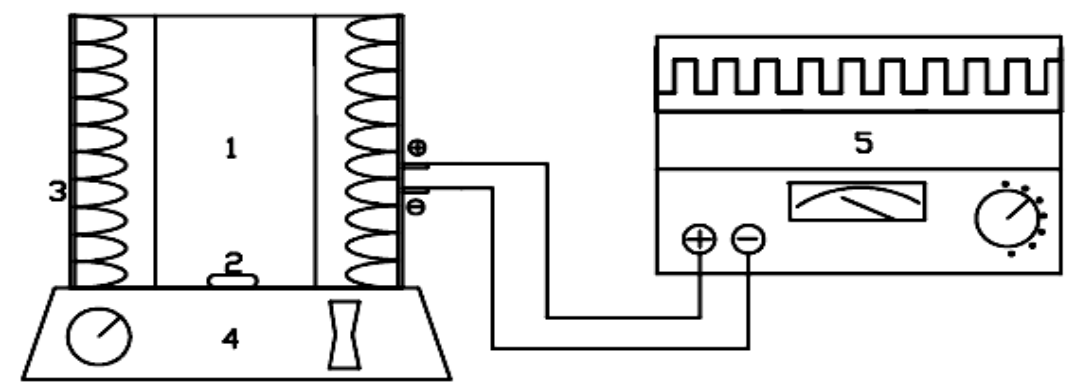

(b)

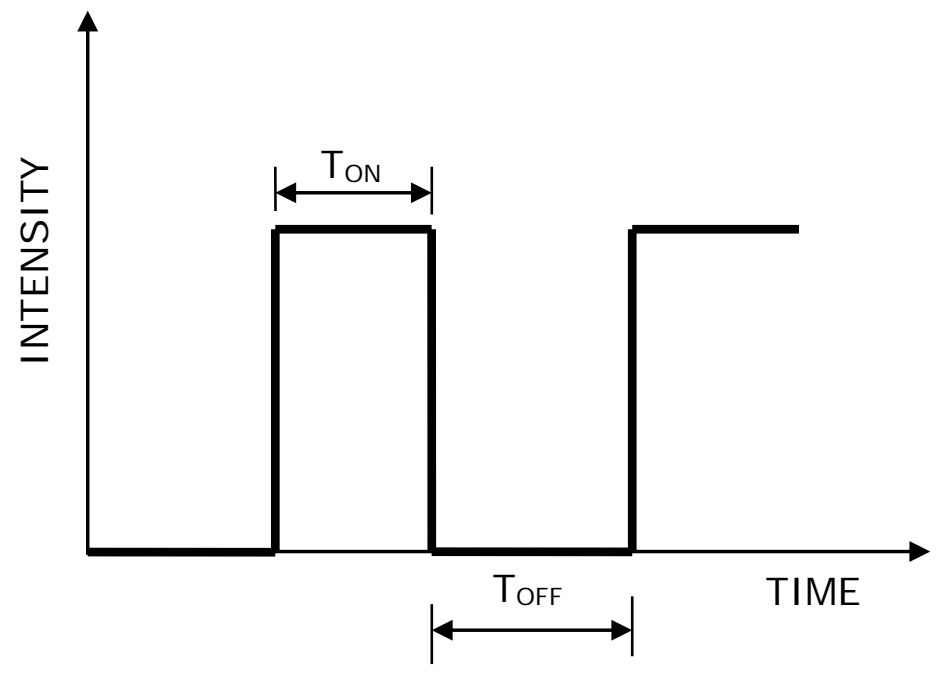

Fig. 1 . 


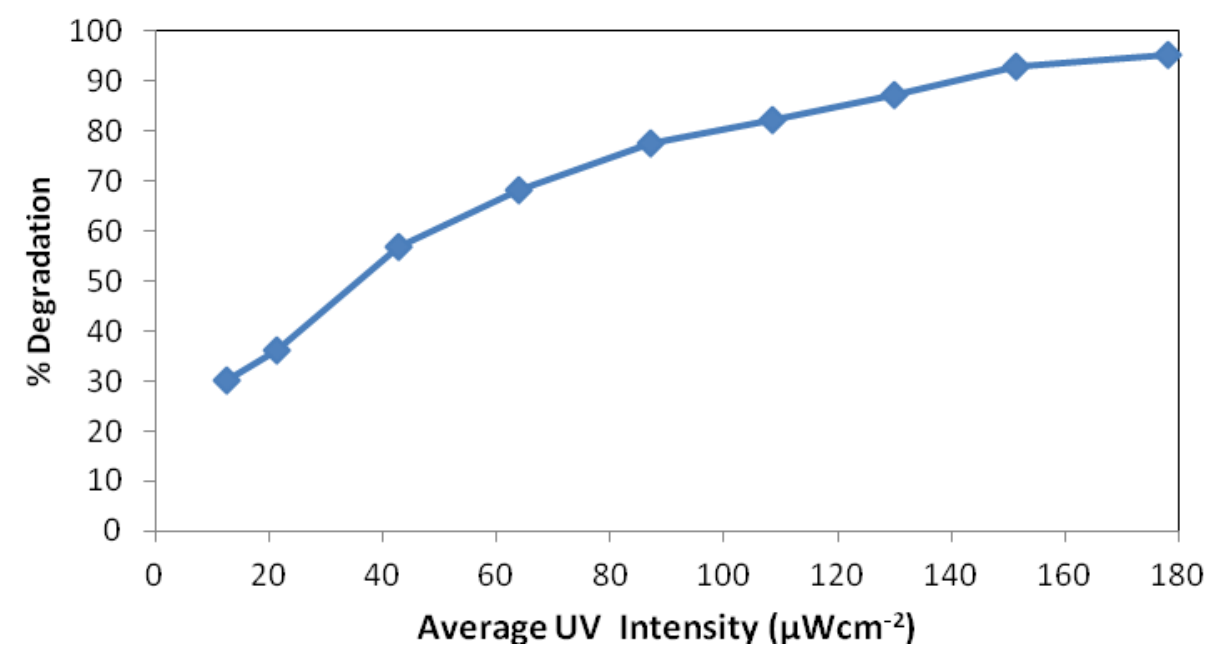

Fig. 2.

(a)

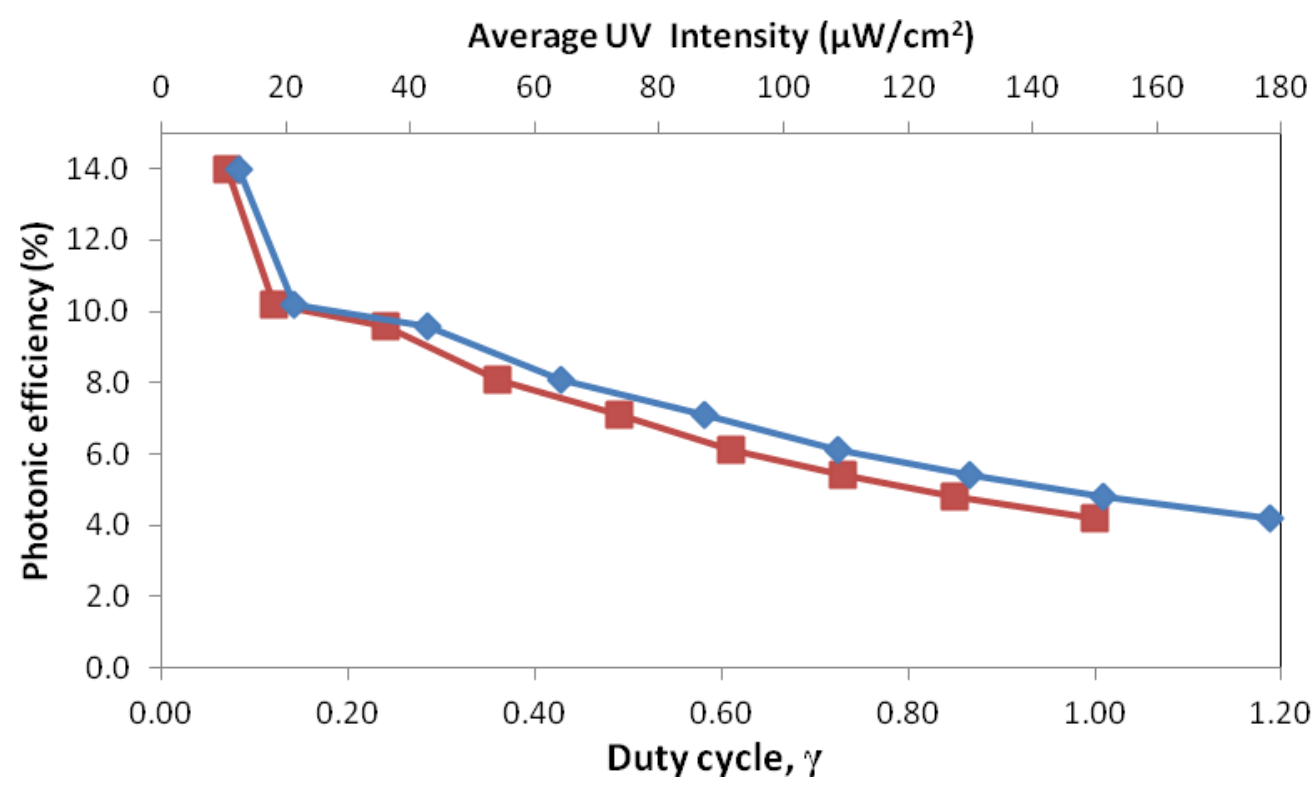


(b)

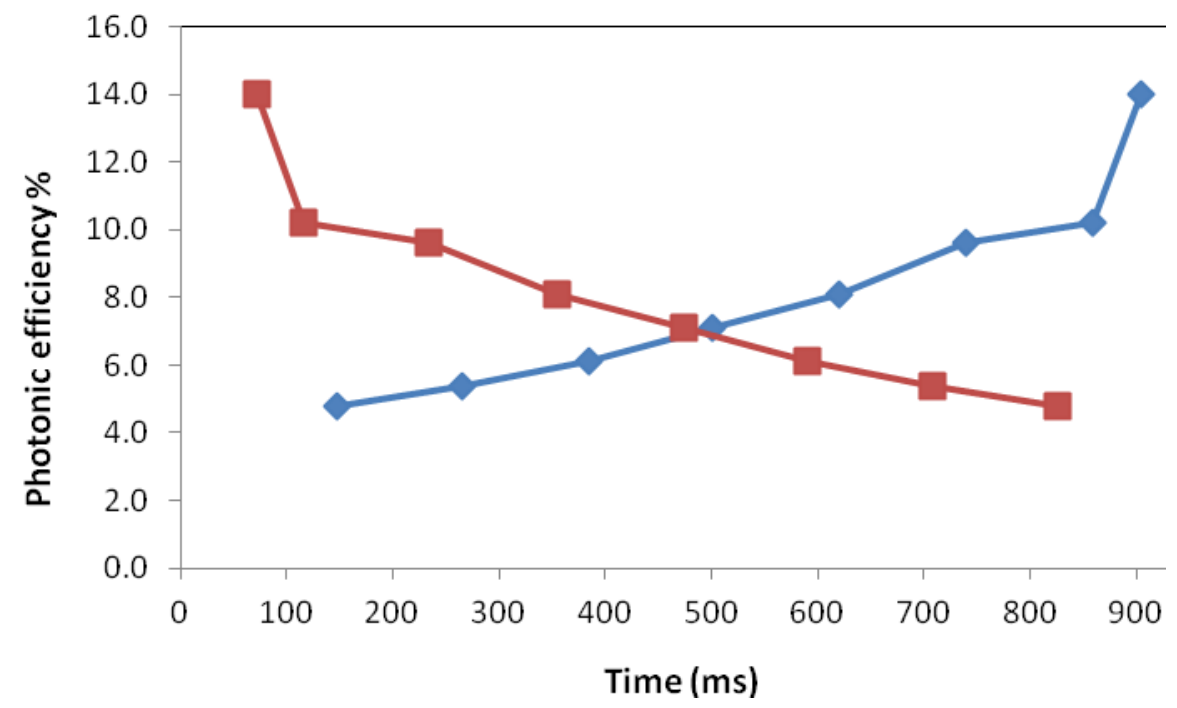

Fig. 3 .

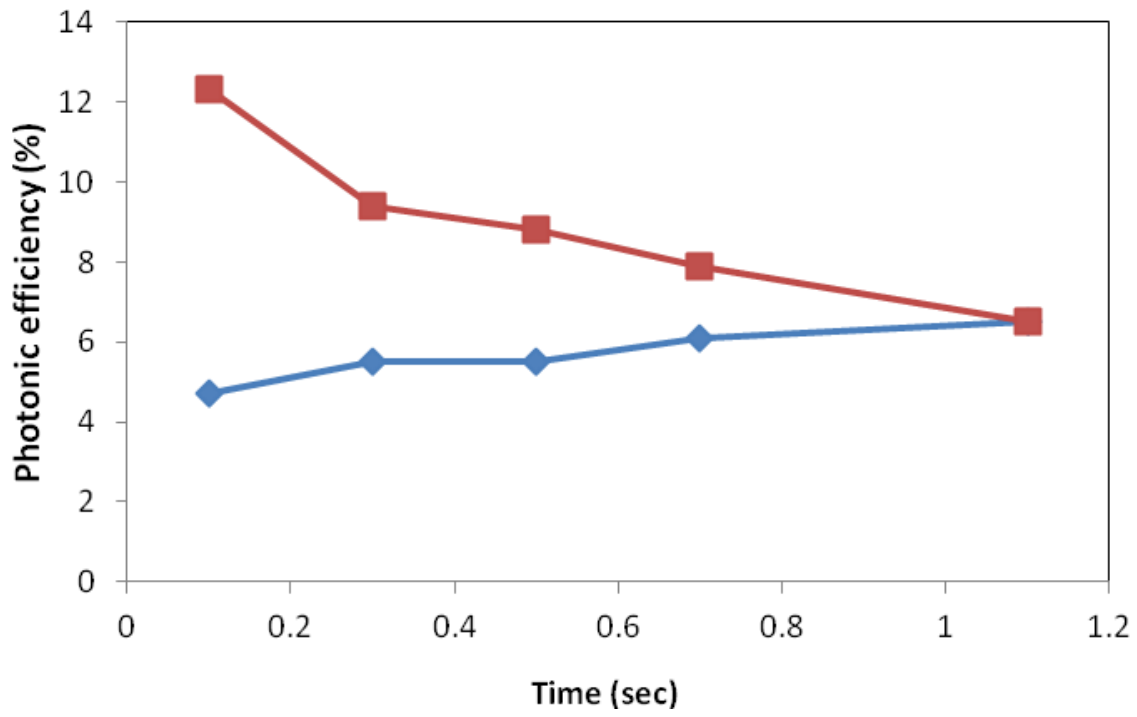

Fig. 4. 


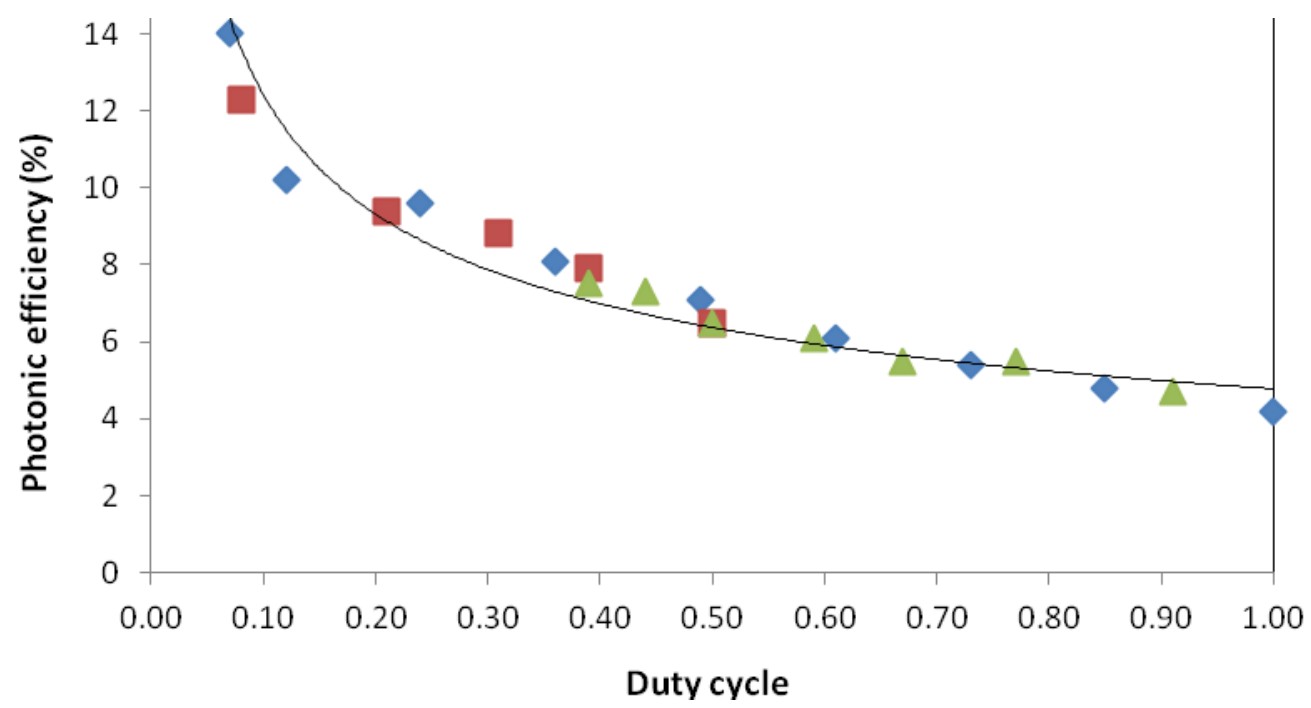

Fig. 5.

(a)

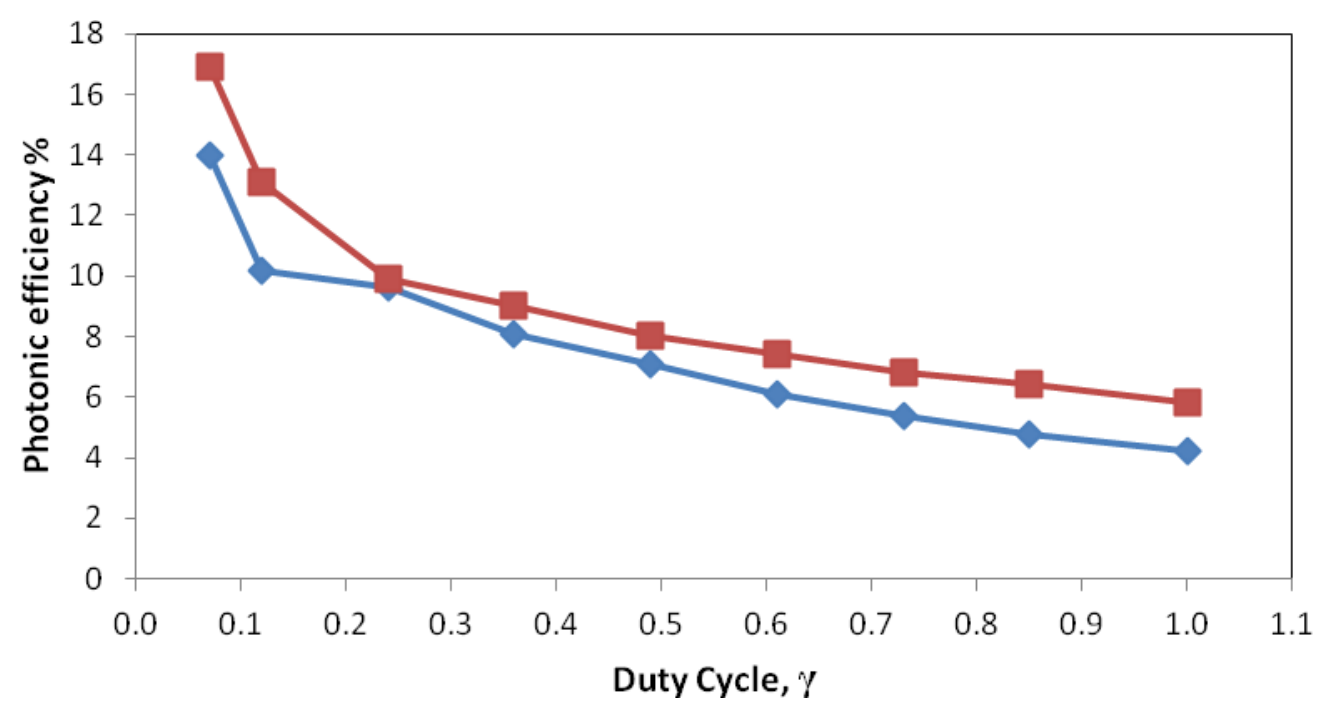


(b)

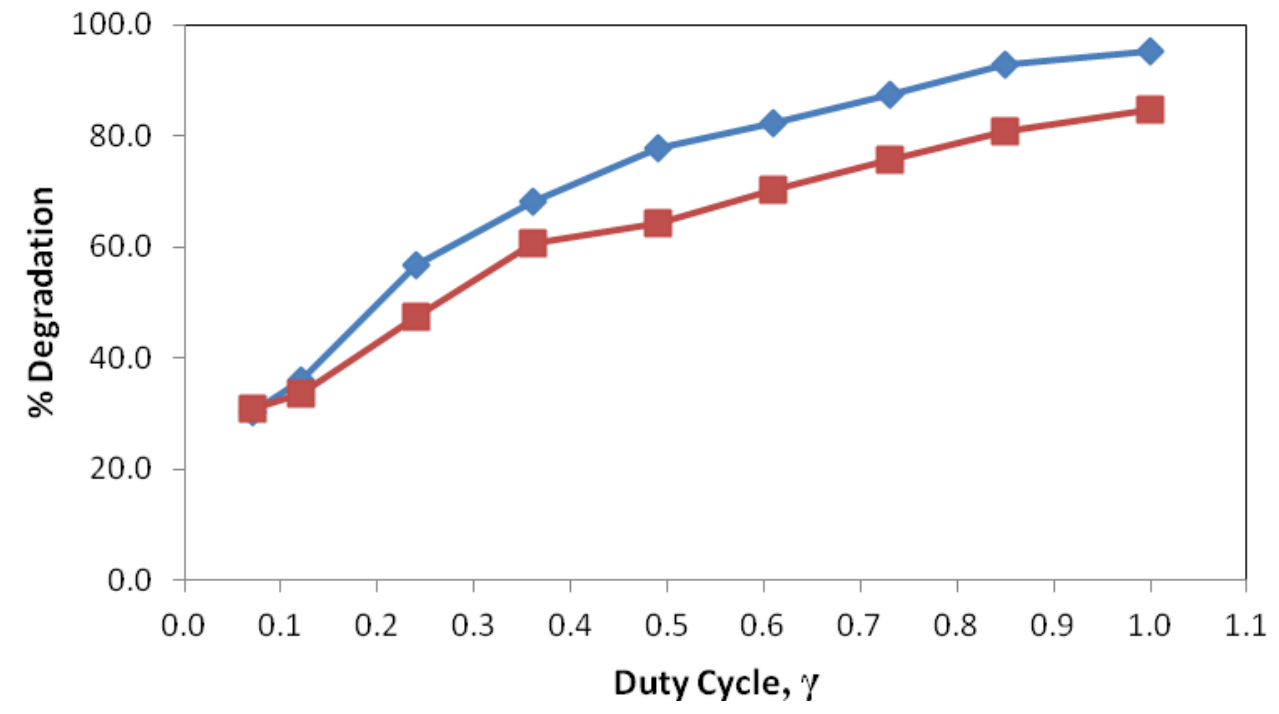

Fig. 6.

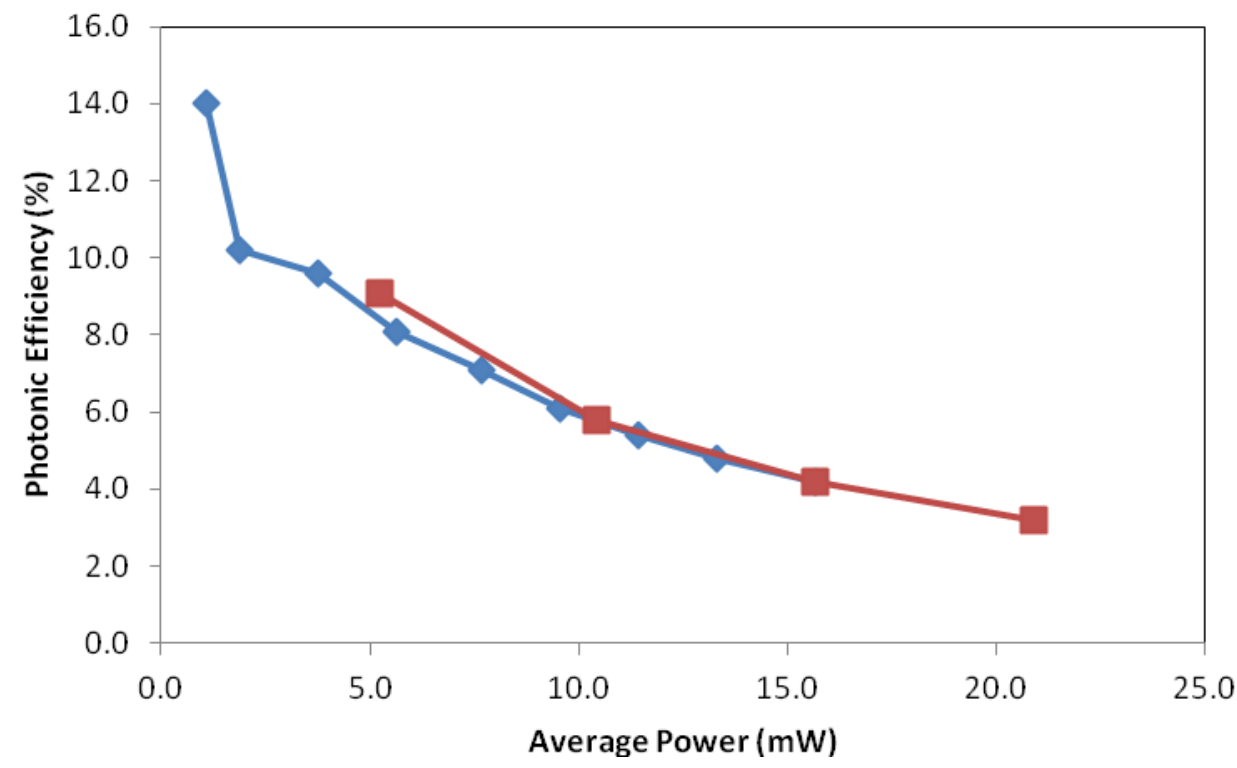

Fig. 7. 